\title{
Supplementary Addendum to "Radiation dose of digital radiography (DR) versus micro-dose x-ray (EOS) on patients with adolescent idiopathic scoliosis: 2016 SOSORT- IRSSD "John Sevastic Award" Winner in Imaging Research"
}

\author{
Steve C. N. Hui and Winnie C. W. Chu*
}

\begin{abstract}
Regarding the publication entitle "Radiation dose of digital radiography (DR) versus micro-dose x-ray (EOS) on patients with adolescent idiopathic scoliosis: 2016 SOSORT- IRSSD "John Sevastic Award" Winner in Imaging Research" in Scoliosis and Spinal Disorders, we would like to provide more details to readers about the dose calculated by simulation using PCXMC 2.0. In this study, the data and results are correct based on the given parameters and calculation provided in the manuscript. In the simulation of EOS micro-dose, only a $0.1 \mathrm{~mm}$ copper filter was applied. We agree with the suggestion from Dr. Pedersen and colleagues that the inclusion of a $1.5 \mathrm{~mm}$ aluminum filter together with the $0.1 \mathrm{~mm}$ copper reflects more realistic representation of X-ray filtration which would improve the accuracy of the simulation. We believe that this supplementary addendum would be beneficial to other researchers who are planning to conduct a similar study.
\end{abstract}

Keywords: Adolescent idiopathic scoliosis, X-ray simulation, Biplanar X-ray

We are writing to provide additional details regarding the article published by Hui et al. (Radiation dose of digital radiography (DR) versus micro-dose $x$-ray (EOS) on patients with adolescent idiopathic scoliosis: 2016 SOSORT- IRSSD "John Sevastic Award" Winner in Imaging Research, Scoliosis Spinal Disord. 2016 Dec 29;11:46. doi: https://doi.org/10.1186/s13013-016-01067.). X-ray filters using copper or aluminum eliminate undesirable low-energy photons which affect the effective dose due to the change of energy spectrum of the $\mathrm{X}$-ray beam and tissue absorption. The dose calculated by simulation using PCXMC 2.0 in this article was solely based on using parameters provided in Table 2 of Hui et al. 2016 which included only a $0.1 \mathrm{~mm}$ copper filter; the inherent $1.5 \mathrm{~mm}$ aluminum filter was omitted. We recalculated effective dose with the additional (aluminum) filtration, and this showed that the average effective dose for the EOS micro-dose protocol would be increased from $2.6 \mu \mathrm{Sv}$ as shown in Table 3 of Hui et al. 2016 to $3.1 \mu \mathrm{Sv}$ similar to the results obtained by Dr. Pedersen and colleagues as both copper and aluminum filters were applied (P. Pedersen, A. Greval and S. Eiskjær, personal communication, July 12, 2017). We suggest using both filters in simulations to determine results that best reflect real circumstance if other investigators plan to conduct similar studies.

\section{Acknowledgements}

We would like to thank Dr. Pedersen, Dr. Eiskjær, and Dr. Greval from the Aalborg University Hospital, Aalborg, Denmark, for their comments to improve the overall accuracy of our simulation process.
* Correspondence: winniechu@cuhk.edu.hk

Department of Imaging and Interventional Radiology, Prince of Wales

Hospital, The Chinese University of Hong Kong, Sha Tin, Hong Kong

\section{Funding}

The original study was partially supported by the SH Ho Scoliosis Research Laboratory (7104486) and Kai Cheong Tong for equipment funding. 


\section{Availability of data and materials}

The dataset supporting the conclusions of this article is included within Hui et al. 2016 and its Additional files.

\section{Authors' contributions}

SH contributed to the analysis and interpretation of data and drafting of the manuscript. WC contributed to the conception and design and critical revision of the manuscript. Both authors read and approved the final manuscript.

\section{Ethics approval and consent to participate}

The research protocol was approved by the Clinical Research Ethics Committee of the institution and conducted in compliance with the principles of Declaration of Helsinki. Written informed consents were obtained from both volunteers and their parent (or legal guardian).

\section{Consent for publication}

Consent to publish has been obtained from all volunteers and their parent or legal guardian.

\section{Competing interests}

The authors declare that they have no competing interests.

\section{Publisher's Note}

Springer Nature remains neutral with regard to jurisdictional claims in published maps and institutional affiliations.

Received: 23 October 2017 Accepted: 22 December 2017

Published online: 08 January 2018

Submit your next manuscript to BioMed Central and we will help you at every step:

- We accept pre-submission inquiries

- Our selector tool helps you to find the most relevant journal

- We provide round the clock customer support

- Convenient online submission

- Thorough peer review

- Inclusion in PubMed and all major indexing services

- Maximum visibility for your research

Submit your manuscript at www.biomedcentral.com/submit 